\title{
Prevalence of serious eye disease and visual impairment in a north London population: population based, cross sectional study
}

\author{
A Reidy, D C Minassian, G Vafidis, J Joseph, S Farrow, J Wu, P Desai, A Connolly
}

\begin{abstract}
Objective: To estimate the magnitude of serious eye disorders and of visual impairment in a defined elderly population of a typical metropolitan area in England, and to assess the frequency they were in touch with, or known to, the eye care services.

Design: Cross sectional survey using two stage cluster random sampling.

Setting: General practices in north London. Subjects: Random sample of people aged 65 and older, drawn from a defined population of elderly people registered with 17 general practice groups. Main outcome measures: Proportions and population prevalence estimates were determined for visual acuity, assessed with the person's own spectacles (if any), classified into four categories: prevalence of cataract, age related macular degeneration, and refractive error causing visual impairment and of definite primary open angle glaucoma; and status of contact with eye services.

Results: 1547 of 1840 (84\%) eligible people were examined. The population prevalence of bilateral visual impairment (visual acuity $<6 / 12$ ) was $30 \%$, of which $72 \%$ was potentially remediable. 92 of these 448 cases $(21 \%)$ had visual acuity $<6 / 60$ ("blindness") in one or both eyes. Prevalence of cataract causing visual impairment was 30\%; $88 \%$ of these people were not in touch with the eye services. The prevalence of vision impairing, age related macular degeneration was $8 \%$ and of glaucoma (definite cases) was 3\%. Three quarters of the people with definite glaucoma were not known to the eye services.

Conclusions: Untreated visual impairment and eye disorders affect a substantial proportion of people aged 65 years and older. These findings should contribute to the setting up of future strategies for preservation of sight and eye health services in general.
\end{abstract}

\section{Introduction}

North Thames Regional Health Authority, and particularly the outer London district health authorities, have not had available to them data from which to project reliable estimates of the magnitude of visual impairment and serious eye disease. This absence of data is equally true for most metropolitan areas in the United Kingdom, with most health authorities having to use the Melton Mowbray findings of 1985 (based on 484 people examined) ${ }^{1}$ and the larger but less relevant American, ${ }^{2}{ }^{3}$ Irish, ${ }^{4}$ and Australian ${ }^{5}$ prevalence studies. Inner London health authorities have had some help from the work carried out by Wormald on visual impairment in 207 elderly patients of a general practice in Camden and Islington. ${ }^{6}$

The North London eye survey is the first completed study of several which aim to rectify the lack of popula- tion based epidemiological assessment of serious eye problems, both those known to the eye services and those previously undetected. When reports are available of the prevalence of eye disease among ethnic groups and in cities such as Leicester and Bristol, public health practitioners and providers of eye services in Britain will have available to them ophthalmic epidemiology data on a par with other Western countries.

The main aims of this study were to obtain estimates of the magnitude of the main serious eye disorders (cataract, age related macular degeneration, primary open angle glaucoma) and of visual impairment in a defined elderly population of a typical metropolitan area in England, and to assess the proportion who were in touch with, or known to, the eye care services. The cross sectional study was designed to draw an unbiased random sample from a defined population in outer London.

\section{Methods}

\section{Sampling}

The chosen geographical area in outer London includes 13371 people aged 65 years or older. It covers six electoral wards and was chosen in consultation with the district health authority and regional health authority for funding under the Primary Care Development Initiative for Service Restructuring in North London This consultation reached agreement that the area studied should have a good mix of socioeconomic characteristics and that all the wards should have similar access to the eye hospital service.

There is ready access to bus and underground transport to the local district general hospital and teaching hospital eye services north and south of the area, and the area is within easy reach of the nation's tertiary eye hospital. The socioeconomic mix can be seen by the Jarman scores $^{7}$ for the wards of the geographical area, which range from 36.06 to -0.88 ; individual indicators show a comparable range (details in table on website).

A two stage cluster random sampling method was used. Of the 17 general practice groups in the eligible wards that constituted the primary (first stage) sampling units, seven were selected at random.

People aged 65 or older who were registered with the practices and confirmed by the Family Health Services Association register constituted the second stage sampling units. The number of such registered people in each primary sampling unit was within the range 750-850. From each of the seven selected primary sampling units, a simple random sample of eligible people was drawn and invited to attend one of four eye examination stations located within easy reach. About a third of the people aged 65 and older registered with each primary sampling unit were thus selected to form the survey sample for this study.

\section{Southampton \\ General Hospital \\ Southampton \\ SO16 6YD \\ A Reidy, \\ senior clinical scientist \\ Institute of \\ Ophthalmology, \\ University College \\ London, London \\ EC1V 9EJ \\ D C Minassian, \\ reader in ophthalmic \\ epidemiology \\ Central Middlesex \\ Hospital, London \\ NW10 7NS \\ G Vafidis, \\ consultant \\ ophthalmologist \\ J Joseph, \\ consultant \\ ophthalmologist \\ A Connolly, \\ research nurse \\ Middlesex \\ University, Enfield \\ N11 2NQ \\ $\mathrm{S}$ Farrow, \\ professor of public \\ health}

Faculty of Medicine,

University of

Southampton,

Southampton

SO9 5NH

P Desai,

senior lecturer in

ophthalmic

epidemiology

$\mathrm{J} \mathrm{Wu}$,

ophthalmology

research fellow

Correspondence to: Dr Minassian

BMJ 1998;316:1643-6

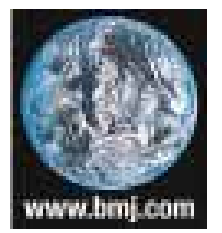




\section{Sample size}

The required sample size was calculated for each of the conditions of interest, making sure that it was large enough to give an adequately precise estimate of prevalence for the least common condition (glaucoma). The additional sampling error expected to arise from the cluster random sampling design was taken into account by incorporating expected "design effect" values of 1.5-3.0 into the equations. A minimum sample size of 1400 was found to be sufficient to give adequately precise prevalence estimates (for example, $95 \%$ probability that the sampling error should not exceed $\pm 1.2 \%$ if glaucoma prevalence is assumed at $4 \%)$. In the event, a total of 1840 people were invited to attend for the eye examinations.

\section{Dealing with non-responders}

The maximum response rate was expected to be $80 \%$ on the basis of prior experience and published reports. People who did not respond to the first invitation from their general practitioner were contacted by one of the survey team to ascertain the difficulty. On the basis of this, further transport and examination centre arrangements were made to maximise response.

\section{Examination}

Age, sex, ethnic origin, relevant medical history, and attendance at primary and secondary eye services were ascertained through interviews before the clinical examination.

Visual acuity was assessed with a distance test chart (LogMar scale) read at six metres with current spectacle correction and through a pin hole, under fluorescent room lighting. Refractive status was ascertained by using the Humphrey 580 autorefractor. Visual fields were assessed in all subjects by the 76 point visual fields of the Humphrey 730 screener, with reading correction. Anterior segment examination was carried out using a slit lamp before lignocaine fluorescein drops were given for Goldmann applanation

Table 1 Population prevalence (\%) of main eye disorders

\begin{tabular}{|c|c|c|c|}
\hline Eye disorder & $\begin{array}{l}\text { No of cases } \\
\text { in sample }\end{array}$ & $\begin{array}{l}\text { Estimated population } \\
\text { prevalence }(95 \% \mathrm{Cl})^{*}\end{array}$ & $\begin{array}{c}\text { Estimated No of } \\
\text { cases in population } \\
\text { of } 13371(95 \% \mathrm{CI})^{\star}\end{array}$ \\
\hline $\begin{array}{l}\text { Cataract (lens opacity; one or both eyes; } \\
\text { visual acuity <6/12) }\end{array}$ & 451 & $30(25.1$ to 35.3$)$ & 4037 (3351 to 4723 ) \\
\hline Had cataract surgery (one or both eyes) & 162 & $10(8.5$ to 12.4$)$ & 1399 (1141 to 1657$)$ \\
\hline $\begin{array}{l}\text { Age related macular degeneration } \\
\text { (visual acuity }<6 / 12 \text { ) }\end{array}$ & 133 & 8 (5.8 to 10.8$)$ & 1108 (776 to 1440$)$ \\
\hline Glaucoma (chronic open angle) & 47 & $3(2.3$ to 3.6$)$ & 395 (306 to 485$)$ \\
\hline Suspected glaucoma & 109 & 7 (5.4 to 8.4 ) & 924 (719 to 1128$)$ \\
\hline $\begin{array}{l}\text { Refractive error causing visual impairment } \\
\text { (one or both eyes; visual acuity }<6 / 12 \text { ) }\end{array}$ & 136 & 9 (7.0 to 11.4$)$ & 1228 (935 to 1521$)$ \\
\hline
\end{tabular}

*Weighted average of cluster specific prevalence measures; calculations take into account the two stage cluster random sampling design.

Table 2 Visual impairment in the population and the proportion likely to be remediable through surgery or refraction and dispensing of spectacles

\begin{tabular}{lccc}
$\begin{array}{l}\text { Visual impairment or blindness } \\
\text { (visual acuity }<\mathbf{6 / 1 2})\end{array}$ & $\begin{array}{c}\text { Estimated population } \\
\text { prevalence (\%) } \mathbf{( 9 5 \%} \mathbf{~ C l )}\end{array}$ & $\begin{array}{c}\text { No of cases in } \\
\text { sample† }\end{array}$ & $\begin{array}{c}\text { Proportion (\%) } \\
\text { potentially } \\
\text { remediable }\end{array}$ \\
\hline One eye only & $23.6(20.9$ to 26.3$)$ & 367 & 65 \\
\hline Both eyes & $30.2(24.8$ to 35.5$)$ & 448 & 72 \\
\hline Total & $53.8(48.4$ to 59.2$)$ & 815 & 69
\end{tabular}

*Weighted average of cluster specific prevalence measures; calculations take into account the two stage cluster random sampling design. †Eye disorders causing visual impairment: cataract, corneal opacity, posterior subcapsular opacity, and refractive error (including uncorrected aphakia or pseudophakia). tonometry. Angle depth was assessed by using comparison with the slit beam width (Van Herick), and gonioscopy was performed if the angle was considered to be abnormally shallow. Pupil reactions were examined before dilatation with tropicamide $1 \%$ drops.

Lens, vitreous, and retinal examinations were done after pupil dilatation. Comparison with LOCS II standard photographs ${ }^{8}$ was used to record cataract type and density. The optic disc and posterior pole were examined by indirect biomicroscopy with 90 dioptre or superfield retinal lenses. The vertical cup:disc ratio of the optic disc was recorded. Peripheral retinal examination was done with an indirect ophthalmoscope.

Visual acuity, autorefraction, and field examinations were carried out by a trained ophthalmic nurse. The remainder of the examination was by ophthalmologists.

\section{Grading and classification}

Visual acuity-For analysis, four "distance" visual acuity groupings were used: $6 / 12$ or better; $<6 / 12$ to $6 / 18 ;<6 / 18$ to $6 / 60$; and worse than $6 / 60$. Visual acuity of $6 / 6$ or better (for example, $5 / 6$ ) indicates normal vision; visual acuity down to and including $6 / 12$ are considered as adequate for driving. Visual acuity $<6 / 12$ may be regarded as impaired vision; visual acuity of less than $6 / 60$ is regarded in many countries (including the United States) as "legal" blindness.

Cataract and age related macular disease-People were classified as having cataract causing visual impairment when the visual acuity in one or both eyes was poorer than $6 / 12$ and the impairment was attributable to a lens opacity. Those with age related macular changes causing visual impairment (visual acuity $<6 / 12$ ) in one or both eyes were classified as having age related macular disease causing visual impairment. These two classes were not exclusive. So that the prevalence of either class would not be underestimated, patients in whom both conditions contributed to the poor vision were included in both classes. Refractive error causing visual impairment was defined as reduced visual acuity of $<6 / 12$ in any eye due only to refractive error.

Glaucoma-An eye was classified as having a visual field defect when there was an absolute defect within 10 degrees of eccentricity, or when there were two or more absolute defects adjacent to each other, or when there were three or more absolute defects in one quadrant. Two ophthalmologists (experienced in glaucoma) working independently categorised the visual fields into normal (absence of defect); abnormal and consistent with glaucoma; or abnormal and consistent with other pathology. Subsequently, disagreements were reconciled by joint reassessment. People were classified as "definite glaucoma cases" when there was an absolute field defect and either a cup:disc ratio of 0.7 or larger or substantial asymmetry of the cups (a difference in cup:disc ratio of 0.3 or larger) between the two eyes. "Glaucoma suspect cases" were those who had an absolute field defect and either a cup:disc ratio of $\geqslant 0.5$ but $<0.7$ or asymmetry of $\geqslant 0.2$ but $<0.3$.

Training in standardised examination methods During a period of 2 months before the field work, workshops were held on examination methods and standardisation wherein agreements were reached between the consultant level ophthalmologists who were to carry out the eye examination and the epidemiologists who designed the study. 


\section{Statistical analysis}

The data were recorded on specially designed forms and were entered into a computer database with facilities for automated and interactive validation of the data. Calculation of the population prevalence estimates and their 95\% confidence intervals used equations appropriate for the two stage cluster random sampling design and took into account the additional variance arising from the cluster sampling method. ${ }^{9}$

\section{Ethical considerations}

Where a condition of a practice's participation in the study was the provision of an eye examination for any patient who requested it, this requirement was strictly adhered to. However, these patients were not included in this study unless they were part of the selected sample. Each person examined was the subject of a follow up letter to the general practitioner, recommending referral to eye clinics when necessary.

\section{Results}

The survey was carried out from April 1995 to October 1996, and 1547 people were examined and included in the sample. Of these, 1459 (94.3\%) were white. Age and sex distribution in the sample was similar to that of the population of the area sampled (figure on website).

\section{Response rate}

The overall response rate was $1547 / 1840(84 \%$ of those invited to participate). This was achieved after up to three rounds of invitation to attend. Non-responders were similar to respondents in terms of age, sex, and attending hospital clinics or opticians. Not having access to a telephone at home was more common in non-responders and in those who had to be re-invited for the third time.

\section{Population prevalence of eye disorders}

Table 1 shows that the population prevalence of visual impairment caused by cataract was $30 \%$, that caused by age related macular degeneration was $8 \%$, and that caused by refractive error was $9 \%$. The prevalence of chronic open angle glaucoma was $3 \%$, and a further $7 \%$ of subjects were suspected of having glaucoma. Table 2 shows that impaired vision in one or both eyes, present in more than half of the sample $(815 / 1547)$, was potentially remediable in $69 \%$ of cases.

Table 3 shows the age specific prevalence of glaucoma and of cataract (including aphakia or pseudophakia). The age adjusted comparison showed a significantly higher prevalence of cataract in women (summary prevalence ratio $=1.22 \quad(95 \%$ confidence interval 1.07 to 1.40$), \mathrm{P}=0.003$ ); this effect was not modified by age $(\mathrm{P}=0.88$, test of equal prevalence across age groups). Glaucoma was more common in men (ratio $=0.70$ (0.35 to 1.10$), \mathrm{P}=0.13$ ) and was not modified by age $(\mathrm{P}=0.53)$. Further adjustment for possible confounding effect of ethnic origin did not materially alter the findings. The sex difference for suspected glaucoma was smaller than that for definite glaucoma (data not shown).

Tentative results on socioeconomic background loosely defined and relating to the Jarman scores in the six wards studied suggest an association between some ophthalmic problems and degree of underprivilege
Table 3 Prevalence of cataract (including aphakia or pseudophakia) and glaucoma (definite cases) in men and women. Cataract is defined as lens opacity causing visual impairment (visual acuity $<6 / 12$ ) in one or both eyes

\begin{tabular}{|c|c|c|c|c|}
\hline \multirow[b]{2}{*}{ Age and sex } & \multicolumn{2}{|c|}{ Cataract } & \multicolumn{2}{|c|}{ Glaucoma } \\
\hline & $\begin{array}{l}\text { Prevalence (\%) } \\
\text { (No of cases) }\end{array}$ & $\begin{array}{c}\text { Prevalence ratio } \\
\text { women:men }\end{array}$ & $\begin{array}{l}\text { Prevalence }(\%) \\
\text { (No of cases) }\end{array}$ & $\begin{array}{l}\text { Prevalence ratio } \\
\text { women:men }\end{array}$ \\
\hline \multicolumn{5}{|l|}{ 65-69: } \\
\hline Women & $17(36 / 213)$ & \multirow{2}{*}{1.08} & $1(3 / 213)$ & \multirow{2}{*}{0.81} \\
\hline Men & $16(27 / 173)$ & & $2(3 / 173)$ & \\
\hline \multicolumn{5}{|l|}{ 70-74: } \\
\hline Female & $27(64 / 238)$ & \multirow{2}{*}{1.27} & $2(5 / 238)$ & \multirow{2}{*}{0.76} \\
\hline Male & $21(38 / 180)$ & & $3(5 / 180)$ & \\
\hline \multicolumn{5}{|l|}{ 75-79: } \\
\hline Female & $44(85 / 195)$ & \multirow{2}{*}{1.3} & $2(3 / 195)$ & \multirow{2}{*}{0.36} \\
\hline Male & $39(55 / 142)$ & & $4(6 / 142)$ & \\
\hline \multicolumn{5}{|l|}{ 80-84: } \\
\hline Female & $64(101 / 159)$ & \multirow{2}{*}{1.32} & $3(4 / 159)$ & \multirow{2}{*}{0.32} \\
\hline Male & $48(37 / 77)$ & & $8(6 / 77)$ & \\
\hline \multicolumn{5}{|l|}{ 85-100: } \\
\hline Female & $76(90 / 119)$ & \multirow{2}{*}{1.29} & $8(9 / 119)$ & \multirow{2}{*}{1.29} \\
\hline Male & $59(30 / 51)$ & & $6(3 / 51)$ & \\
\hline \multicolumn{5}{|l|}{ All: } \\
\hline Female & $41(376 / 924)$ & \multirow{3}{*}{1.36} & $3(24 / 924)$ & \multirow{3}{*}{0.70} \\
\hline Male & $30(187 / 623)$ & & $4(23 / 623)$ & \\
\hline All & $36(563 / 1547)$ & & $3(47 / 1547)$ & \\
\hline
\end{tabular}

CATARACT: Age adjusted summary prevalence ratio* $=1.22$ ( $95 \%$ confidence limits $1.07-1.40, P$ value 0.003$)$ Test of equal prevalence across the age groups: $P$ value $=0.88$ (indicates no effect of modification by age) *Remains highly significant after further adjustment for possible confounding effect of "ethnic origin" GLAUCOMA: Age adjusted summary prevalence ratio** $=0.70$ (95\% confidence limits $0.35-1.10, P$ value 0.13 ) Test of equal prevalence across the age groups: $P$ value $=0.53$ (indicates no effect modification by age) ** Slightly reduced (to 0.63 , not significant) after further adjustment for possible confounding effect of "ethnic origin"

Table 4 Age standardised prevalence of poor vision, and causal disorders, in three distinct socioeconomic groups, north London. Group 3 comprises residents of the most underprivileged areas (Jarman score 36.06); group 2, residents of areas with intermediate scores $(33.98,18.51$, and 21.35); and group 1, residents of the least underprivileged areas (scores -0.88 and 0.35 ). The age structure of the whole sample was used as the standard

\begin{tabular}{|c|c|c|c|c|c|c|}
\hline \multirow[b]{2}{*}{ Condition (in one or both eyes) } & \multicolumn{3}{|c|}{$\begin{array}{l}\text { No (age standardised \%) } \\
\text { in socioeconomic group }\end{array}$} & \multicolumn{3}{|c|}{$\begin{array}{l}\text { P values for comparison } \\
\text { of groups* }\end{array}$} \\
\hline & $\begin{array}{c}1 \\
(n=757)\end{array}$ & $\begin{array}{c}2 \\
(n=203)\end{array}$ & $\begin{array}{c}3 \\
(n=587)\end{array}$ & $1 v 2$ & $1 v 3$ & $2 v 3$ \\
\hline \multicolumn{7}{|l|}{ Visual impairment or blindness: } \\
\hline Visual acuity $<6 / 12$ in one or both eyes & $354(45)$ & $104(55)$ & $357(61)$ & 0.039 & 0.016 & 0.046 \\
\hline Visual acuity $<6 / 12$ in both eyes & $164(20)$ & $60(34)$ & $224(39)$ & 0.005 & 0.002 & 0.007 \\
\hline \multicolumn{7}{|l|}{ Main contributing conditions: } \\
\hline Refractive error causing visual impairment & $43(6)$ & $18(8)$ & $75(12)$ & 0.016 & 0.011 & 0.005 \\
\hline Cataract causing visual impairment & $181(23)$ & $69(38)$ & $201(35)$ & 0.004 & 0.032 & 0.767 \\
\hline Age related macular disease & $81(10)$ & $10(6)$ & $42(8)$ & 0.013 & 0.299 & 0.426 \\
\hline
\end{tabular}

${ }^{*}$ From logistic regressions taking into account the cluster sampling design effect.

Table 5 People with visual impairment or glaucoma not in touch with eye care services

\begin{tabular}{lcc} 
& $\begin{array}{c}\text { No of } \\
\text { cases }\end{array}$ & $\begin{array}{c}\text { No }(\%) \text { not in } \\
\text { touch with } \\
\text { eye care services }\end{array}$ \\
\hline Cataract causing visual impairment & 451 & $397(88)$ \\
\hline $\begin{array}{l}\text { Age related macular disease causing } \\
\text { visual impairment }\end{array}$ & 133 & $114(86)$ \\
\hline Refractive error causing visual impairment & 136 & $131(96)^{*}$ \\
\hline Glaucoma: & 156 & $126(81)$ \\
\hline Definite cases & 47 & $35(74)$ \\
\hline Suspect cases & 109 & $91(84)$ \\
\hline
\end{tabular}

*39/131 (30\%) had visited an optometrist during the past 12 months.

(table 4). The age standardised prevalence of poor vision was significantly higher in the residents of the most underprivileged areas, the main contributing disorders being refractive error and cataract. 


\section{Contact with eye services}

For definite glaucoma, the ratio of undetected to known cases was 3:1, and for suspected glaucoma the ratio was 5:1. Overall, $88 \%$ of people with visual impairment or glaucoma were not in touch with eye care services (table 5). A total of 698 people $(45 \%$ of the total sample) had visited an optometrist within the 12 months preceding the survey eye examination.

\section{Discussion}

Visual acuity was assessed with the person wearing his or her spectacles, so that the day to day vision, rather than the potential best possible vision, was measured. This allowed prevalence estimates that reflect the actual visual impairment problem existing at the time of the survey. Recent studies such as the Baltimore eye survey, ${ }^{10}$ the US Salisbury eye evaluation study, ${ }^{11}$ and the Blue Mountain eye study $y^{5}$ have reported the visual acuity after refraction and best correction at the time of the survey.

Major difficulties in comparing results from different surveys arise from non-standardised definitions, criteria, and examination methods. ${ }^{12}$ Glaucoma is particularly problematic as there is no generally agreed definition for it. The criteria used in our study to define a case of primary open angle glaucoma were clearly defined and set at a higher severity of optic disc damage than those used in several earlier studies and were similar to those in a much cited Australian study. ${ }^{13}$ Detailed comparison of our findings with other studies, therefore, would not be fruitful. In spite of the stringent criteria, the prevalence of glaucoma was substantial and the number of people who should be monitored as suspects considerable.

Our study used a cut off for visual acuity of $6 / 12$ to define visual impairment. This is in line with the cut off used in the Baltimore eye survey and with the minimum legal requirement for driving. Using the $6 / 12$ cut off for visual acuity should allow health agencies to be alerted to the full spectrum of clinically important visual impairment in the population. Of the 448 people found to have impaired vision in both eyes, the visual acuity in the worst affected eye was within the limits $<6 / 12$ to $6 / 18$ in $19 \%,<6 / 18$ to $6 / 60$ in $61 \%$, and $<6 / 60$ ("blindness") in the remaining $21 \%$. The distribution is thus skewed towards more severe visual impairment. Of the 451 patients with visually impairing cataract, $310(69 \%)$ had visual acuity of $<6 / 18$, with 51 $(11 \%)$ being "blind" (visual acuity $<6 / 60$ ) from cataract in one or both eyes.

\section{Key messages}

- Data have not been adequate to reliably estimate the extent of visual impairment and serious eye disease in metropolitan areas in Britain

- Data from north London shows that $30 \%$ of a sample of the population aged 65 or older are visually impaired in both eyes

- More than $72 \%$ of the bilateral visual impairment was potentially remediable by surgery or glasses, nearly one in three people had visually impairing cataract, and $88 \%$ of these people were not in touch with eye services

- Eye problems were more prevalent in people living in relatively underprivileged areas
Most of this morbidity was not known to the eye services. Several factors could be responsible for the high level of undetected and untreated morbidity in the population. These are, firstly, inadequate levels of attendance at the high street optometrist or failure to purchase corrective spectacles; secondly, suboptimal integration of vision checks into the general primary care of elderly people, possibly linked with a reluctance to add to the lengthy waiting lists; and, thirdly, patients' perspectives on the extent to which their vision has gradually diminished, the point at which help should be sought, and uncertainties about the treatment and the outcome. We have recently completed a follow up study of the survey cohort, which should help us to identify and to quantify some of the deficits in the pathway to care for people with impaired vision.

We thank the members of the public who responded to the survey and the general practitioners, practice nurses, and practice managers for their cooperation. We thank the chief executive of Barnet Health Authority, Ms J Hargadon, for cooperation and support. We appreciate the painstaking work of members of the clinical team of Central Middlesex Hospital Eye Unit who carried out the eye examinations, and we acknowledge the contribution of Don Fraser, our eye research administrator for many projects, and John Drummond, the independent data management consultant. Thanks also to Dr Carol Brayne of the University of Cambridge Institute of Public Health and to Tim Hellings, locality manager, for his foresight in helping us obtain support for the survey and the finance staff for their tolerance with the many demands we made on their time and patience.

Contributors: AR was principal investigator and took part in development, conduct, and completion of the study; DCM was the epidemiologist in charge of independent monitoring and data analysis; GV was an examining ophthalmologist and in charge of general clinical standardisation; JJ was an examining ophthalmologist and in charge of visual fields assessment; SF was concerned with public health aspects of primary care screening and sampling; JXW was the psychophysicist and external visual fields assessor; PD was responsible for measurement and standardisation of comorbidity data collection; AC was responsible for all ophthalmic nursing research aspects of the study. DCM and AR are guarantors of this report.

Funding: North Thames Regional Health Authority Special Funding Initiative, District Primary Care Development Fund, and North Thames Regional Research and Development.

Conflict of interest: None.

1 Gibson JM, Rosenthal AR, Lavery J. A study of the prevalence of eye disease in the elderly in an English community. Trans Ophthalmol Soc UK $1985 ; 104: 196-203$

2 Leibowitz HM, Krueger DE, Maunder LR. The Framingham eye study monograph: an ophthalmological and epidemiological study of cataract, glaucoma, diabetic retinopathy, macular degeneration, and visual acuity in a general population of 2631 adults, 1973-1975. Surv Ophthalmol 1980:24(suppl):335-610.

3 Tielsch JM, Sommer A, Witt K, Katz J, Royall RM. Blindness and visual impairment in an American urban population: the Baltimore eye survey. Arch Ophthalmol 1990;108:286-90.

4 Coffey M, Reidy A, Wormald R, Wu X, Wright L, Courtney P. Prevalence of glaucoma in the west of Ireland. BrJ Ophthalmol 1993;77:17-21.

5 Attebo K, Mitchell P, Smith W. Visual acuity and causes of visual loss in Australia. Ophthalmology 1996;103:357-64.

6 Wormald RPL, Wright LA, Courtney P, Beaumont B, Haines AP. Visual problems in the elderly population and implications for services. BMJ 1992;304:1226-9

7 Jarman B. Underprivileged areas: validation and distribution of scores. BMJ 1984;289:1587-92.

8 Chylack LT Jr, Leske MC, Sperduto R, Khu P, McCarthy D, LOCS Research Group. Lens opacities classification system. Arch Ophthalmol 1988;106:330-4.

9 Cochran W. Sampling techniques. New York: John Wiley, 1977.

10 Rahmani B, Tielsch JM, Katz J, Gottsch J, Quigley H, Javitt J, et al. The cause-specific prevalence of visual impairment in an urban population: the Baltimore eye study. Ophthalmology 1996;103:1721-6.

11 Rubin GS, West SK, Muñoz B, Bandeen-Roche K, Zeger S, Schein O, et al. A comprehensive assessment of visual impairment in a population of older Americans: the SEE study. Invest Ophthalmol Vis Sci 1997;38:557-68.

12 Livingston PM, Carson CA, Taylor HR. The epidemiology of cataract: a review of the literature. Ophthal Epidemiol 1995;2:151-64.

(Accepted 4 February 1998) 